\title{
Patch Loaded DRA for Broadband WLAN Applications
}

\author{
Archana Sharma, Kavita Khare, S.C.Srivastava, Zarreen Aizaz \\ Maulana Azad National Institute of Technology, Bhopal, India
}

\begin{abstract}
A wideband patch loaded dielectric resonator antenna (DRA) is discussed here. The rectangular ring shaped slot coupling is used to excite the proposed antenna. In this paper, rectangular ring shaped slot coupled DRA and patch loaded DRA is studied and compared. The combined effect of patch radiator with rectangular ring shaped slot coupled DRA, on the return loss is observed. Simulation is done using Ansoft HFSS which is based on finite element method. Simple DRA resonates at two frequencies centered at $2.25 \mathrm{GHz}$ having return loss of $14.41 \mathrm{db}$ and $4.61 \mathrm{GHz}$ with a return loss of $-19.29 \mathrm{db}$; The patch loaded DRA shows resonance at frequencies centered around $2.19 \mathrm{GHz}$ having return loss of $-32.3 \mathrm{db}$ and $4.4 \mathrm{GHz}$ with a return loss of $-29.18 \mathrm{db}$.The patch loaded DRA is based on the multi resonance technique that combines the resonance of slot coupled dielectric resonator and micro strip patch antenna. The bandwidth achieved for simple DRA is $26.8 \%$ while patch loaded DRA offers $44.1 \%$.As the patch loaded DRA has larger bandwidth, may be used for wideband WLAN applications like WiFi, Bluetooth, Wimax etc.
\end{abstract}

\section{General Terms}

Broadband, WLAN, antenna

\section{Keywords}

Bandwidth, DRA, Multi-resonance, patch, slot coupling.

\section{INTRODUCTION}

Over the past few years' researchers were focusing on investigations of dielectric-resonator antenna (DRA) technology as an alternative to traditional antennas due to its high radiation efficiency, lightweight, small size, low profile and low dissipation loss [19-22].

DRA is a resonant antenna, fabricated from low-loss dielectric material, the resonant frequency of which is predominantly a function of size, shape, and material permittivity [20]. Bandwidths of up to $10 \%$ can be easily achieved with simple rectangular DRA; that cannot fulfill the requirement of broadband/wireless applications. So, various approach has been investigated to enhance the bandwidth of DRA as stacking multiple DRAs, using parasitic dielectric resonator elements, introducing the air gap, slot coupling, thick substrate etc[11-18]. Many bandwidth enhancement techniques investigated earlier increases the overall size and volume of the DRA antenna which can limits its use in portable device. Compact slot and dielectric resonator antenna with dual resonance \& broadband characteristic has been investigated [8]. In this paper the novel approach has been introduced to enhance the bandwidth of simple DRA with maintaining its miniaturized size. The simple rectangular DRA-fed by ring slot coupling, is shown in Fig (1). The design is modified to enhance the bandwidth of simple DRA by loading the patch antenna on top of DRA [1]. The impedance bandwidth is a function of the material's permittivity and aspect ratio. For proposed simple DRA, a return-loss bandwidth of $8.7 \%$ and $18.1 \%$ for $2.25 \mathrm{GHz}$ and $4.61 \mathrm{GHz}$ respectively are obtained. The micro-strip feed line is preferred over probe coupling to avoid spurious radiations. Coupling depends on the slot dimensions \& DRA position on it. Microstrip stub also cancels out the reactive component of the slot that is not covered in this paper. The implemented design is based on multi-resonance technique in which the resonance of slot coupled dielectric resonator antenna and patch antenna has been combined to improve the bandwidth of DRA without increasing the volume of the antenna design.

\section{DESIGN CONCEPT AND ANTENNA CONFIGURATION}

As discussed earlier, the slot dimension and permittivity of sub- and supersaturate (DRA) determine the frequencies of slot resonances, while the DRA modes depend on the DR dimensions, permittivity, as well as the feeding mechanism [21-23]. The method used in the proposed design is multiresonance technique [8]. For feeding the antenna geometry micro strip feed line is used. To couple the energy to the DRA rectangular ring shaped slot coupling is used. DRA is loaded on the ring slot structure. The dimensions of the DRA is so chosen that (if $\mathrm{L}_{\mathrm{dra}}, \mathrm{W}_{\mathrm{dra}}<\mathrm{h}_{\mathrm{dra}}$ ), height can be given by the relation $h_{d r a}$ equals to $\lambda_{0} / 4\left(\varepsilon_{\text {dra }}\right)^{-1 / 2}$. Slot dimensions are taken in terms of free space wavelength i.e. $\lambda_{0}[1]$. Then the antenna geometry is modified by using patch on the top of DRA to improve bandwidth. Ansoft HFSS is used for simulating the antenna design and seeing the result.

\subsection{Feed line}

A $50 \mathrm{ohm}$ microstrip line with the length of $3 \mathrm{~cm}$ and width $0.157 \mathrm{~cm}$ is positioned just below the center of the DRA. A 50 ohm coaxial SMA connector is used to feed the microwave power to the feed line.

\subsection{Substrate}

A thin substrate layer of FR 4 having low dielectric constant of 4.4 is used with thickness $0.165 \mathrm{~cm}$.Length and width of it is chosen as $5 \mathrm{~cm} \times 5 \mathrm{~cm}$.

\subsection{Slot}

Rectangular ring slot is used with dimension $\mathrm{L}_{\mathrm{s} 1} 2 \mathrm{~cm}, \mathrm{~L}_{\mathrm{s} 2} 1 \mathrm{~cm}$ and $\mathrm{W}_{\mathrm{s}} 0.2 \mathrm{~cm}$. Rectangular slot is used for maintaining the symmetry with rectangular DRA.

\subsection{Patch}

Micro strip Patch of dimension $3.12 \mathrm{~cm} \times 2.44 \mathrm{~cm}$ is etched on DRA top. It is designed as to cover the complete top surface of DRA.

\subsection{DRA Dimensions}

Rectangular DRA of dielectric constant 11.9 with the size length $\left(\mathrm{L}_{\text {dra }}\right)=3.12 \mathrm{~cm}$, width $\left(\mathrm{W}_{\text {dra }}\right) 2.44$, height $\left(\mathrm{h}_{\text {dra }}\right) 1.2 \mathrm{~cm}$ is considered. 
The two designs has been simulated with and without the patch radiator. The figure 1 and 2 shows the DRA without the patch. Figure 3 and 4 shows DRA design with patch on top of

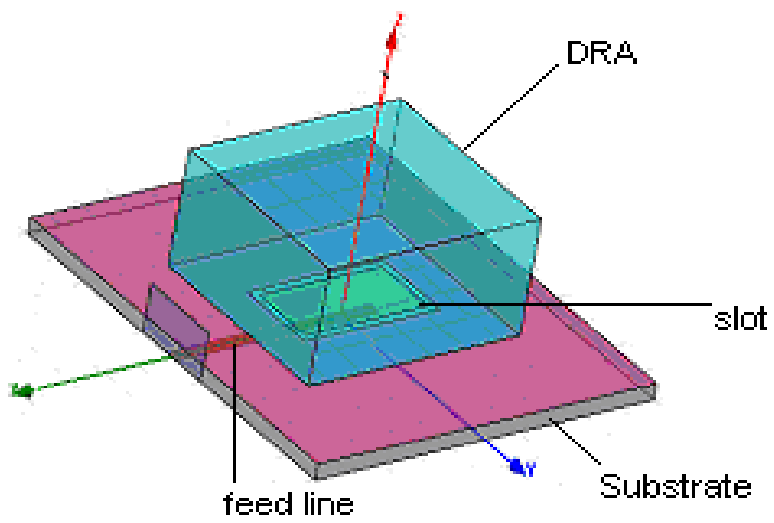

Figure 1: Simple rectangular ring shaped slot coupled DRA (HFSS view)

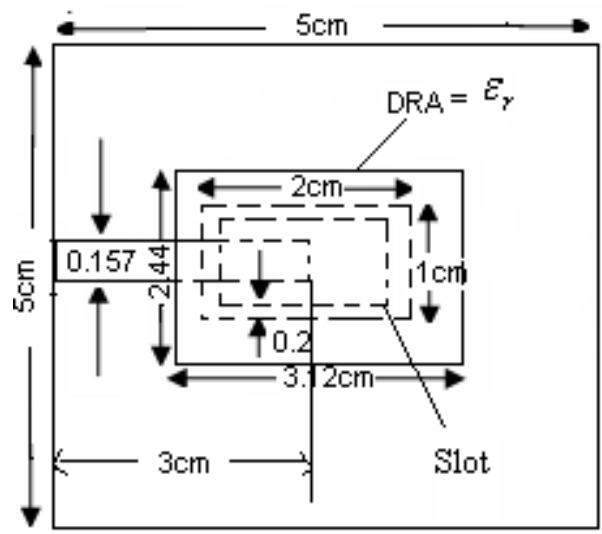

Figure 2: Simple rectangular ring shaped slot coupled DRA (HFSS view)

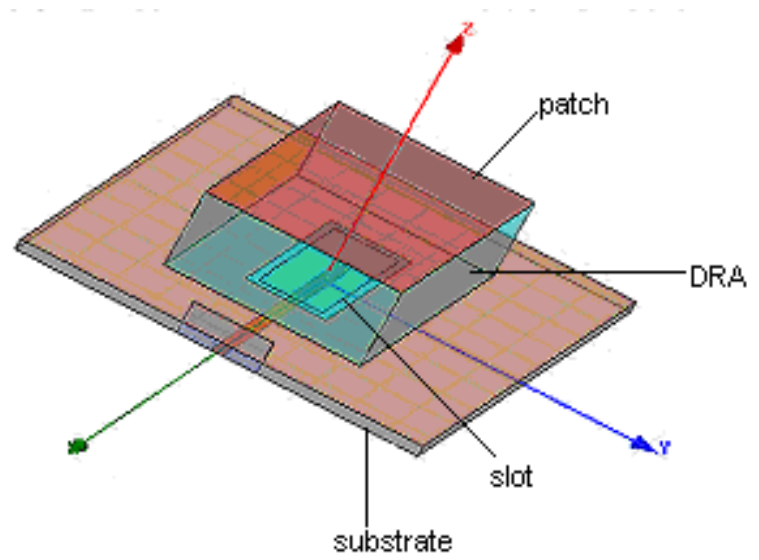

Figure 3 Rectangular slot coupled Patch Loaded DRA (HFSS view)

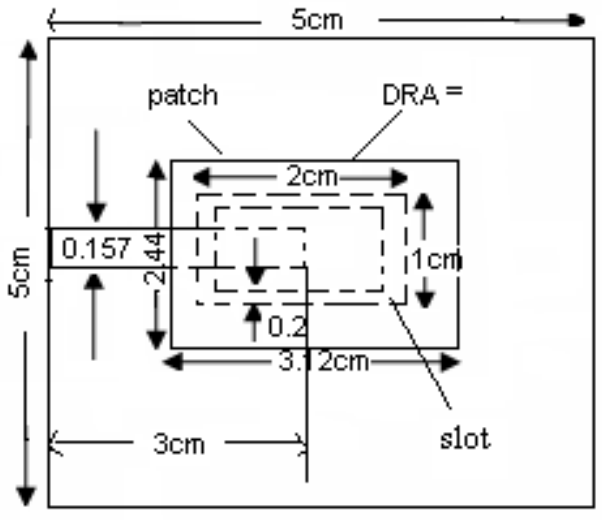

Figure 4: Rectangular slot coupled Patch Loaded DRA (top view)

\section{RESULTS \& DISCUSSION}

The antenna designs (SDRA and PLDRA) based on the multiresonance technique and gives dual band operation. The resonant frequencies of simple DRA are obtained around 2.25 $\mathrm{GHz}$ and $4.61 \mathrm{GHz}$ while that of the patch loaded DRA (PLDRA) is obtained around $2.19 \mathrm{GHz}$ and $4.4 \mathrm{GHz}$. The return loss graph with respect to frequency for both the designs is shown in fig (5) and fig (6).

The $\%$ bandwidth is calculated from return loss verses frequency plot and is given by:

$\mathrm{BW}(\%)=\left(\mathrm{f}_{\mathrm{H}^{-}}-\mathrm{f}_{\mathrm{L}}\right) / \mathrm{f}_{\mathrm{C}}$

where $f_{C}=\left(f_{H}+f_{L}\right) / 2$ and $f_{H}, f_{L}$ are high cut off frequency and low cut off frequency respectively.

The return loss bandwidth for simple design is $8.7 \%$ and $18.1 \%$ at $2.25 \mathrm{GHz}$ and $4.61 \mathrm{GHz}$ respectively. The patch loaded DRA gives the bandwidth of around $500 \mathrm{MHz}$ at resonant frequency $2.19 \mathrm{GHz} \& 970 \mathrm{MHz}$ at frequency 4.4 GHz. Hence the PLDRA gives dual band operation with improved bandwidth of $20.8 \%$ and $23.3 \%$.

The resonant frequencies in PLDRA are shifted to $2.19 \mathrm{GHz}$ and $4.4 \mathrm{GHz}$ respectively due to the effect of patch antenna. So, it would be useful for lower microwave frequency applications mainly for mobile communication. The bandwidth of PLDRA is improved due to combined effect of patch with DRA. The return loss is above $-10 \mathrm{db}$ between the frequency range $2.65 \mathrm{GHz}$ to $4.1 \mathrm{GHz}$ that lowers the performance over this frequency range. This problem can be overcome by changing dielectric constant and size of DRA.

The return loss can be further lowered by optimizing the design parameters of DRA, patch and using the stub matching method. The radiation pattern for SDRA and PLDRA at 2.2 $\mathrm{GHz}$ is shown in fig 7 and 8 respectively. The radiation characteristic of PLDRA is maintained as that of SDRA.FBR (front to back ratio) of SDRA is $12.7 \mathrm{db}$ with gain $16.82 \mathrm{dbi}$ at 2.2GHz. PLDRA gives the FBR of $7.04 \mathrm{db}$ with gain of 9.26 dbi at desired frequency $2.2 \mathrm{GHz}$. PLDRA offers improved bandwidth with reasonably good gain. 
Table 1 Return loss, resonant frequencies and bandwidth of SDRA and PLDRA

\begin{tabular}{|l||l|l|l|l|l|l|}
\hline Results & $\begin{array}{l}\text { Resonant } \\
\text { freq(GHz) }\end{array}$ & $\begin{array}{l}\text { Min } \\
\text { Return } \\
\text { loss(db) }\end{array}$ & $\begin{array}{l}\text { Operating } \\
\text { frequency } \\
\text { range(GHz) }\end{array}$ & BW & BW \% & $\begin{array}{l}\text { FBR } \\
(\mathbf{d b})\end{array}$ \\
\hline $\begin{array}{l}\text { Simple } \\
\text { DRA }\end{array}$ & 2.25 & -14.41 & $2.2-2.4$ & 200 & 8.7 & \\
\cline { 2 - 7 } & 4.61 & -19.29 & $4.25-5.1$ & 850 & 18.1 & 12.7 \\
\hline $\begin{array}{l}\text { Patch } \\
\text { loaded } \\
\text { DRA }\end{array}$ & 4.4 & -32.3 & $2.15-2.65$ & 500 & 20.8 & \\
\cline { 2 - 7 } & & -29.18 & $4.13-5.1$ & 970 & 23.3 & 7.04 \\
\hline
\end{tabular}

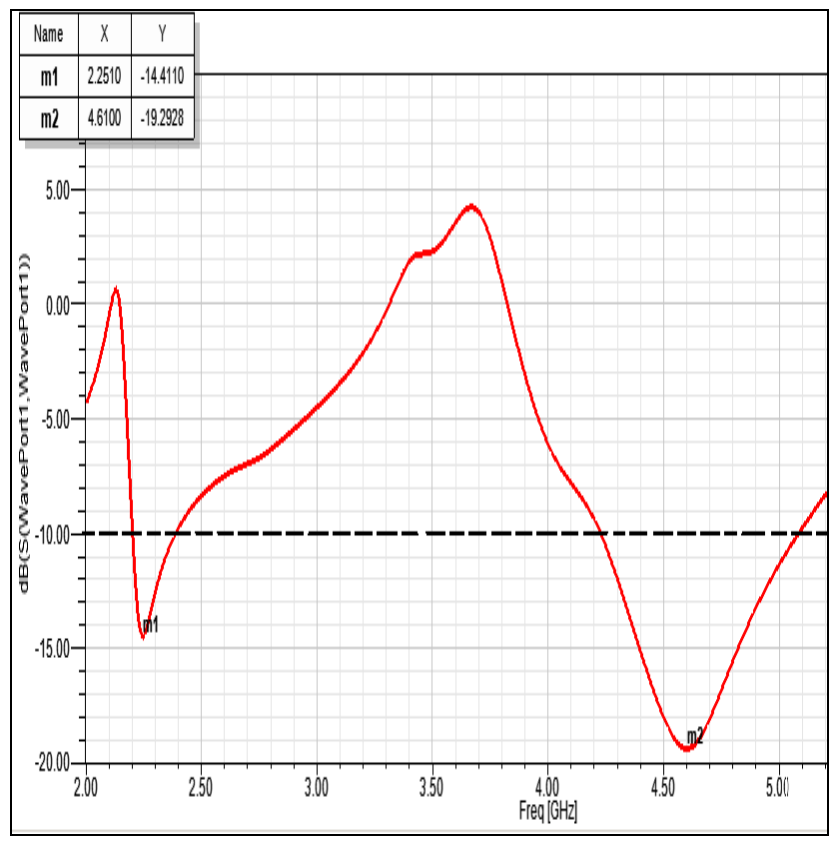

Figure 5: Return loss of rectangular ring slot coupled DRA (Simple DRA)

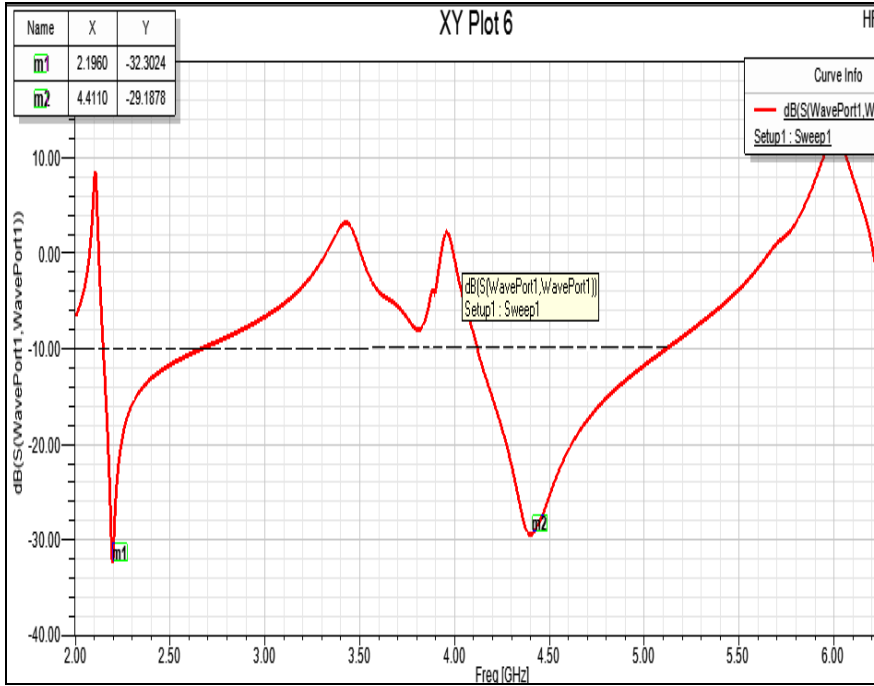

Figure 6: Return loss of patch loaded DRA 1 (dielectric constant 11.9)

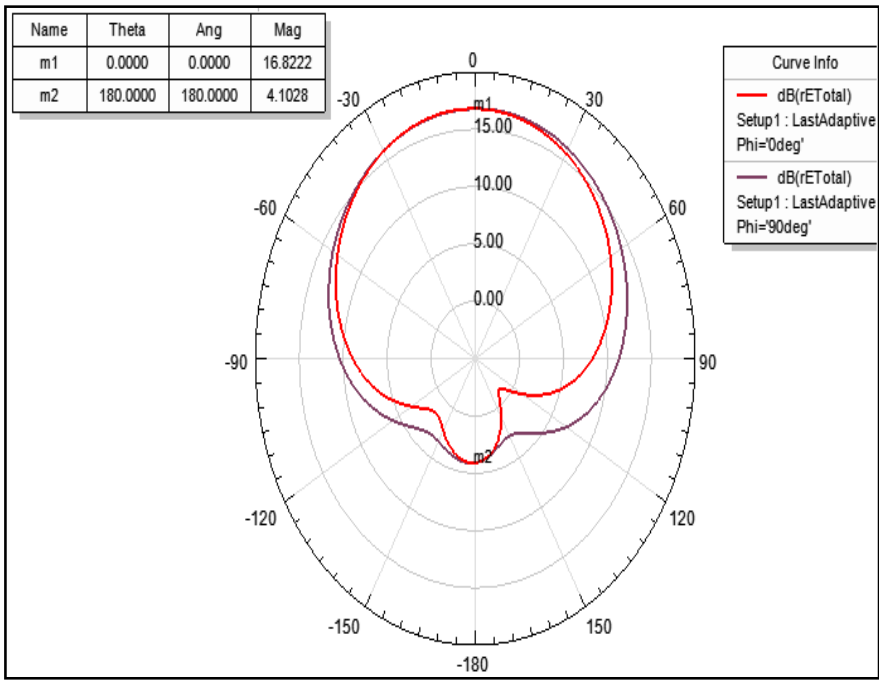

Figure 7: Radiation pattern of SDRA at $2.2 \mathrm{GHz}$

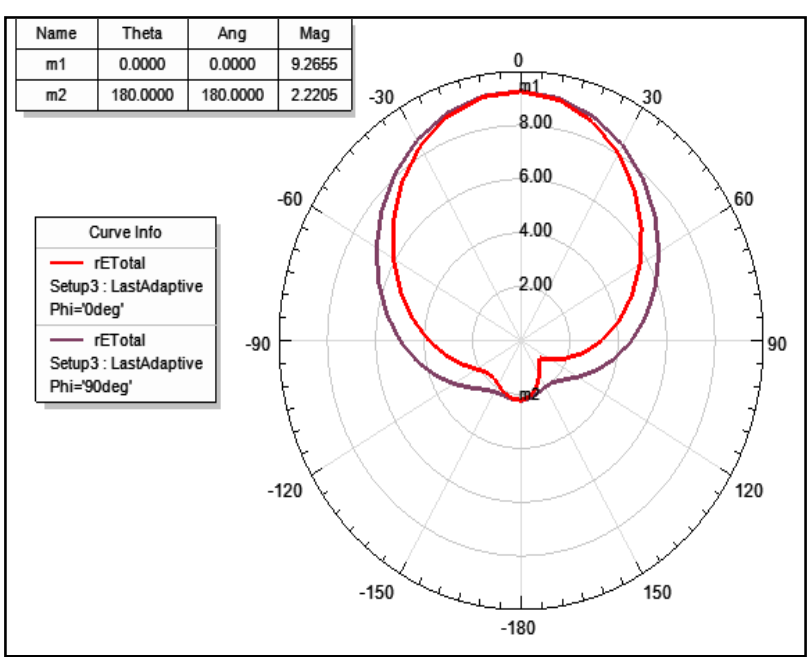




\section{Figure 8 Radiation pattern of PLDRA at 2.2 GHZ.}

\section{CONCLUSIONS}

In this communication, broadband patch loaded DRA has been proposed. The resonance of the slot and DRA is merged with the patch antenna to get broadband characteristics. This broadband antenna design can be useful for mobile communication, WLAN, IEEE 802.16 WiMAX applications with the operating frequency band $2.15-2.65 \mathrm{GHz}$ and 4.13 $5.1 \mathrm{GHz}$. From the analytical and comparative study it has been observed that the combination of patch antenna and DRA gives broadband characteristics. Thus; the PLDRA is better choice than simple DRA because it gives much wider bandwidth (44.1\%) whereas simple DRA offers bandwidth of $26.8 \%$. As PLDRA is having minimum return loss of $-32 \mathrm{db}$ at frequency $2.19 \mathrm{GHz}$ and return loss of -29.18 at $4.4 \mathrm{GHz}$, improved matching is achieved. The patch loaded DRA has been introduced as an antenna for broad band applications without compromising with miniaturization of the antenna design. The drawback of increased volume of previous bandwidth enhancement techniques (such as stacking multiple DRAs, multi segment DRA or introducing air gap) is reduced in the proposed method.

\section{REFERENCES}

[1] P. M. Hadalgi et al., "Slot fed wideband dielectric resonator for wireless application," Indian Journal of Radio \& Space Physics, vol. 39, pp.372-375, Dec 2010.

[2] T. A. Denidni and Z. Weng, "Rectangular dielectric resonator antenna for ultra wideband applications," Electronics Letters, vol. 45, no. 24, Nov. 2009.

[3] Atabak Rashidian and David M. Klymyshyn, "On the two segmented and high aspect ratio rectangular dielectric resonator antennas for bandwidth enhancement and miniaturization," IEEE Transactions on Antennas And Propagation, vol. 57, no. 9, pp. 2775-2780, September 2009

[4] Nasmuddin and K. Esselle, "Antennas with dielectric resonators and surface mounted short horns for high gain and large bandwidth," IET Proc. Microwave Antennas Propag., vol. 1, no. 3, pp. 723-729, Jun. 2007.

[5] Yuan Gao et al, "A compact Wideband Hybrid Dielectric Resonant Antenna", IEEE Microwave and wireless components Letters, Vol. 16 No.4,pp. 227-229, April 2006.

[6] Amelia Buerkle et al.,"Compact slot and dielectric resonator antenna with dual resonance, broadband characteristics", IEEE Trans. On Antennas and Propagation, vol.4, pp. 1020-1024, March 2005.

[7] Ahmed A. Kishk, "Experimental Study of Broad Band Embedded Dielectric Resonator Antennas Excited by a narrow Slot", IEEE trans. Antennas and Wireless Propagation Letters, Vol.4, Jan 2005

[8] X. Q. Sheng et al., "Analysis of waveguide-fed dielectric resonator antenna using a hybrid finite element method," IEE proc. Microwave Antenna Propagation, vol. 151, no. 1,pp. 91-95, Feb 2004.
[9] Kumar Vaibhav Srivastava et al, "A Modified Ring Dielectric Resonator With Improved Mode Separation In MIC Environment", 34th European Microwave Conference - Amsterdam, pp. 609-612, 2004

[10] Ahmed A. Kishk, numerical analysis of stacked dielectric resonator antennas excited by a coaxial probe for wideband applications", IEEE Trans. On Antennas and propagation, vol. 51, no.8, pp. 1996-2006, August 2003.

[11] M. S. Al Salameh, Y. M. M. Antar, and G. Séguin, "Coplanar-Waveguide-Fed Slot-Coupled Rectangular Dielectric ResonatorAntenna," IEEE Trans. Antennas Propagat., vol. 50, pp. 1415-1419,Oct.2002.

[12] Kut Yuen Chow and Kwok Wa Leung, "Theory and experiment of the cavity-backed slot-excited dielectric resonator antenna," IEEE Trans. on Electromagnetic Compatibility, vol. 42, no. 3, pp .290-296, August 2000.

[13] Aldo Petosa, Neil Simons et al., "Design and analysis of multisegment dielectric resonator antennas," IEEE Trans. On Antennas And Propagation, vol. 48, no. 5, pp. 738 742 , May 2000

[14] Petosa, A. Ittipibon, "Recent advances in dielectricresonator antenna technology," IEEE Antennas and Magazine, vol. 40, no. 3, pp. 35-43, June 1998.

[15] Rajesh kumar Mongia et al., "Theoretical and experimental investigations on rectangular dielectric resonator antennas," IEEE Trans. on Antennas and propagation, vol. 45, no.9, pp. 1350-1355, Sept. 1997.

[16] G.P. Junker, A.A Kishk et al, "Effect of air gap on cylindrical dielectric resonator antenna operating in TM01 mode," Electronics Lettes, vol. 30, no. 3, pp 97 98,Jan 1994.

[17] G. M. Tusi, H.Shigesawa et al,“Analytical and experimental investigations on several resonant modes in open dielectric resonators", IEEE Trans. Microwave Theory Tech., pp 628-633, June 1984.

[18] Long, S. A., M. W. McAllister, and G. L. Conway, "Rectangular dielectric resonator antenna," Electronics Letters, Vol. 19, No. 6, 218-219, March 1983.

[19] James K. Plourde, “Application of Dielectric Resonators in Microwave Components", IEEE Trans. on Microwave theory And Techniques, Vol MTT-29, No. 8, August 1981.

[20] Tatsuo Itoh et al.,"New method for computing the resonant frequencies of dielectric resonators", IEEE Trans. on Microwave Theory and Techniques, Jan 1977.

[21] Shiban K.Kaul.,"Millimeter wave \& optical dielectric integrated guide and ckt", Wiley series in microwave \& optical engg, series editor.

[22] Luk K.M. \& Lueng, "Dielectric resonator antennas" Electronic \& Electrical Engg. Research Series, pp 65-80, 1967.

[23] Temex, "Dielectric materials", User guide 